\title{
Selection of the Best Proposal using FAHP: Case of Procurement of IT Master Plan's Realization
}

\author{
Amadou Diabagaté ${ }^{1}$, Abdellah Azmani ${ }^{2}$, Mohamed El Harzli ${ }^{3}$ \\ ${ }^{1,2}$ Department of Computer Science, Faculty of Sciences and Technologies, University Abdel Malek Essaadi, Morocco \\ ${ }^{3}$ Department of Electrical Engineering, Faculty of Sciences and Technologies, University Abdel Malek Essaadi, Morocco
}

\begin{abstract}
Article Info
Article history:

Received Oct 4, 2016

Revised Dec 20, 2016

Accepted Jan 4, 2017

\section{Keyword:}

Artificial intelligence

Fuzzy AHP

IT master plan

Multi-criteria decision making

Tendering

ABSTRACT

IT master plan, which allows planning and managing the development of the computer systems, derives its importance in the central role of the computer systems in the functioning of organizations. This article focuses on the use of FAHP method for analysis and evaluation of tenders during the awarding of contracts of IT master plan's realization. For those purposes, a painstaking work was realized for making an inventory of criteria and sub-criteria involved in the evaluation of tenders and for specifying the degrees of preference for each pair of criteria and sub-criteria. To find a provider for the IT master plan's realization, organizations are increasingly using tendering as the mode of awarding contracts. This paper is an improvement of a previous published paper in which AHP method was used. The goals of this work are to make available to members of tenders committee a decision support tool for evaluating tenders of IT master plan's realization and endow the organizations with effective IT master plans in order to increase their information systems' performance.
\end{abstract}

Copyright $\odot 2017$ Institute of Advanced Engineering and Science. All rights reserved.

\section{Corresponding Author:}

Amadou Diabagaté,

Department of Computer Science,

University Abdel Malek Essaadi, Ziaten, Tangier 413, Morocco.

Email: ahmadou.diabagate@gmail.com

\section{INTRODUCTION}

Organizations increasingly use IT master plan for leading the development of the computer system which is an essential element for their operations [1]. Thus, public and private procurement of IT master plan's realization are becoming more frequent.

The IT master plan is a strategic plan intended for piloting the development of IT in an organization. It allows having a computer system that meets the strategic options of the Directorate General. Its starting point is the strategy of an organization to reach the definition of a target in terms of IT and information system. The realization of an IT master plan aims at many objectives such as the urbanization of the computer system, the modernization of IT infrastructures (hardware and software), the reduction of IT costs, the accompaniment of the launch of strategic projects, the creation of monitoring indicators, the multi-sites deployment of the computer system.

Organizations, in order to ensure their tasks, need to purchase goods or services or to execute work. These purchases designated by the term "procurement" play a considerable economic role and have a significant economic weight [2] estimated at about $20 \%$ of global GDP [3]. The award of contracts is a sensitive area as the economic interests at stake are huge [3], [4]. There are several modes for awarding contracts including tendering [5] which can be defined as a process that allows to emit a request for works, services and goods to businesses and then choose the provider after analysis of proposals according to predetermined criteria without negotiation [6]. 
The analysis and evaluation of tenders is a decisive step in the tendering process [7], [8]. The principle established to analyze and evaluate tenders is based on the use of awarding criteria [9]. These criteria must be designed so as to be nondiscriminatory and linked to the object of the contract. Thus, the selection of the best tender can be characterized as a multiple criteria decision-making (MCDM) problem. A frequently used method to solve the MCDM problems is AHP (Analytic Hierarchy Process) method [10], [11] which has been developed by the mathematician Thomas Saaty Lorie [12]. It is a powerful and flexible method of decision support applied for solving simple and complex problems in many situations [13], [14].

FAHP (Fuzzy Analytic Hierarchy Process) method is an improvement of the AHP method which itself contains some shortcomings. In particular, its effectiveness is reduced in solving problems with vague and imprecise information [15] in which FAHP is more adapted [16], [17]. There are various FAHP methods, the first was proposed in 1983 by Van Laarhoven and Pedrycz [18]. The FAHP method proposed by Chang, which is used in this paper, has two main advantages namely the great similarity with the basic method AHP and few computations during its implementation [19]. For these advantages, the most of the recent applications of FAHP use the Chang method [18].

To improve the process of selecting the best tender, many solutions based on artificial intelligence methods particularly on multi-criteria decision making methods have been proposed [20], [21]. Tsai and Chou have worked on the establishment of a fuzzy system for online awarding contracts that allows bidders submitting tenders online. The tenders will be evaluated online by the fuzzy system according the awarding criteria [22]. Diabagaté et al. have proposed a new method of analysis and evaluation of tenders based on the use of fuzzy logic and rule of proportion [23]. Regarding the multi-criteria decision making methods, AHP and FAHP seem be very popular methods and have been widely applied to deal with various complex decision-making problems mainly the problem of selecting the best tender [18-24]. Thus, Priya et al. have developed a decision support system in the context of the dematerialization of public procurement for the choice of the best tender among which proposed by auto manufacturing companies. They integrated AHP method in this e-procurement system for the selection of the best proposal [24]. Atanasova-Pacemska et al. have proposed a decision making tool for the choosing of the best economic offer for purchase of computer equipment, especially purchase of desktop computers. In this research, the selection criteria according to which the selection of the best bid will be made is in accordance with the Law on Public Procurement of the Republic of Macedonia [25]. Aydin and Kahramanproposed AHP based analytical tool for decision support enabling an effective multi-criteria supplier selection process in an air conditioner seller firm under fuzziness. In this work, the Analytic Hierarchy Process (AHP) under fuzziness is employed for its permissiveness to use an evaluation scale including linguistic expressions, crisp numerical values, fuzzy numbers and range numerical values [26]. Chan and Kumar proposed a model for providing a framework for an organization to select the global supplier by considering risk factors. They used fuzzy extended analytic hierarchy process in the selection of global supplier [27]. Ayhanhas applied Fuzzy AHP in a gear motor company for determining the best tender among which submitted by companies with respect to selected criteria [28]. Tas proposed a fuzzy analytic hierarchy process (fuzzy-AHP) to efficiently tackle both quantitative and qualitative criteria involved in selection of global supplier in pharmaceutical industry. For this study, four main criteria and thirteen sub-criteria were identified for supplier selection in this problem [29]. Shaw et al. developed an integrated approach for selecting the appropriate supplier in the supply chain, addressing the carbon emission issue, using fuzzy-AHP and fuzzy multi-objective linear programming. Fuzzy AHP (FAHP) is applied first for analyzing the weights of the multiple factors. These weights of the multiple factors are used in fuzzy multi-objective linear programming for supplier selection and quota allocation [30].

The aim of this work is to propose a decision making tool that allows selecting the best tender during the contracts awarding of information technology (IT) master plan's realization. To achieve that, the FAHP method has been used for its performance and its great success in published works. In the literature, we have not found the published research using FAHP which address the selection of the best tender during awarding contracts of IT master plan's realization. This fact reflects the great importance of this work which can be considered as reference by organizations during tendering of IT master plan's realization.

\section{PRESENTATION OF FAHP METHOD}

FAHP is a multi-criteria decision support method which combines AHP method and the concepts of fuzzy sets [31], [32].

\subsection{Fuzzy Sets and Fuzzy Numbers}

The concept of fuzzy set was introduced for the first time in 1965 by Lotfi Zadeh to correct the limitations of classical logic due to the imprecision and vagueness [33], [34]. Since its introduction, the fuzzy 
set theory has been widely used in the resolution of many problems in which decision makers need to analyze and process imprecise and vague information [17], [18].

A fuzzy set $A=\left\{\left(x, \mu_{A}(x)\right) \mid x \in X\right\}$ is a set of ordered pairs where $X$ is a subset of the real numbers $R$ and $\mu_{A}(x)$ is a membership function that assigns to each object $x$ a grade of membership ranging from 0 to 1 .

A fuzzy number $M=\left\{\left(x, \mu_{M}(x)\right) \mid x \in X\right\}$ is a particular case of fuzzy set which membership function obeys to the conditions of normality $\left(\sup \mu_{M}(x)=1, x \in X\right)$ and convexity $\left(\mu_{M}\left(\gamma * x_{1}+\left(1-\gamma * x_{2}\right)\right) \geq \min \left\{\mu_{M}\left(x_{1}\right), \mu_{M}\left(x_{2}\right)\right\}, x_{1}\right.$ et $\left.x_{2} \in X, \gamma \in[0,1]\right)[13]$.

There are several types of fuzzy numbers, the most used being the triangular and trapezoidal fuzzy numbers [35], [36]. Given that this paper is using the FAHP method introduced by Chang which uses triangular fuzzy numbers [37]. Thus, triangular fuzzy numbers will be taken to present the properties of fuzzy numbers. Let $M=(l, m, u)$ be a triangular fuzzy number, its membership function $\mu_{M}$ is defined by:

$$
\mu_{M}(x)= \begin{cases}\frac{x}{m-l}-\frac{l}{m-l}, & x \in[l, m] \\ \frac{x}{m-u}-\frac{u}{m-u}, & x \in[l, u] \\ 0, & \text { otherwise }\end{cases}
$$

where $l \leq m \leq u, l$ and $u$ are respectively the smallest and the largest of the support of $M$ and $m$ is the median value of $M$. The support of $M$ is the set defined assupp $(M)=\{x \in R / l<x<u\}$. If $l=m=u$ then, by convention, $M$ is not a fuzzy number. Let $M_{1}=\left(l_{1}, m_{1}, u_{1}\right)$ and $M_{2}=\left(l_{2}, m_{2}, u_{2}\right)$ be two fuzzy numbers, the main rules on their mathematical operations are as follows:

$$
\begin{aligned}
& \left(l_{1}, m_{1}, \quad u_{1}\right) \oplus\left(l_{2}, m_{2}, \quad u_{2}\right)=\left(l_{1}+l_{2}, m_{1}+m_{2}, \quad u_{1}+u_{2}\right) \\
& \left(l_{1}, \quad m_{1}, \quad u_{1}\right) \odot\left(l_{2}, \quad m_{2}, \quad u_{2}\right) \approx\left(l_{1} * l_{2}, \quad m_{1} * m_{2}, \quad u_{1} * u_{2}\right) \\
& \lambda \odot\left(l_{1}, \quad m_{1}, \quad u_{1}\right)=\left(\lambda * l_{1}, \lambda * m_{1}, \lambda * u_{1}\right) \lambda>0, \quad \lambda \in R \\
& \left(l_{1}, \quad m_{1}, \quad u_{1}\right)^{-1} \approx\left(1 / u_{1}, 1 / m_{1}, 1 / l_{1}\right)
\end{aligned}
$$

\subsection{Theory of FAHP Method}

The implementation of FAHP method with a view to choosing the best alternative is done in two main phases. The first phase consists in the construction of a matrix of judgment, the determination of the values of fuzzy synthetic extents, the calculation of degrees of possibility and the determination of weight vector (priority vector) [38]. The second phase consists in making a comparative study of alternatives in order to choose the best [12-39]. The steps and the mathematical theory of the second phase are similar to those of the first phase.

Step of construction of judgment matrix: let $\tilde{A}$ be the matrix of judgment or comparison, $\tilde{A}$ is defined as follows:

$$
\tilde{A}=\left(\begin{array}{ccccc}
M_{11} & M_{12} & \cdots & \cdots & M_{1 m} \\
M_{21} & M_{22} & \cdots & \cdots & \cdots \\
\cdots & \cdots & \ddots & \cdots & \cdots \\
\cdots & \cdots & \cdots & \ddots & \cdots \\
M_{n 1} & \cdots & \cdots & \cdots & M_{n m}
\end{array}\right)=\left(M_{i j}\right)_{1 \leq i \leq n ; 1 \leq j \leq m} \text { where }_{i j}=\left(l_{i j}, \quad m_{i j}, \quad u_{i j}\right)
$$

In the matrix $\tilde{A}$, the decision maker sets the preferences with respect to each pair of criteria and each pair of sub criteria. These preferences, which are expressed as verbal forms by the decision maker are converted [40] to fuzzy number forms. For the Chang method, the conversion scale in table 1 can be used [19]. 
Table 1. Triangular Fuzzy Conversion Scale

\begin{tabular}{ccc}
\hline Linguistic scale & Triangular fuzzy scale & Triangular fuzzy reciprocal scale \\
\hline Just equal & $(1,1,1)$ & $(1,1,1)$ \\
Equally important & $(1 / 2,1,3 / 2)$ & $(2 / 3,1,2)$ \\
Weakly important & $(1,3 / 2,2)$ & $(1 / 2,2 / 3,1)$ \\
Strongly more important & $(3 / 2,2,5 / 2)$ & $(2 / 5,1 / 2,2 / 3)$ \\
Verystrongly more important & $(2,5 / 2,3)$ & $(1 / 3,2 / 5,1 / 2)$ \\
Absolutely important & $(5 / 2,3,7 / 2)$ & $(2 / 7,1 / 3,2 / 5)$ \\
\hline
\end{tabular}

Step of the determination of fuzzy synthetic extent: the determination of the values of Fuzzy Synthetic Extents (FSE) for each criterion has been done using the following formula:

$$
S_{i}=\sum_{j=1}^{m} M_{i j} \odot\left[\sum_{i=1}^{n} \sum_{j=1}^{m} M_{i}\right]^{-1}
$$

where

$$
\begin{aligned}
& \sum_{j=1}^{m} M_{i j}=\left(\sum_{j=1}^{m} l_{i j}, \sum_{j=1}^{m} m_{i j}, \sum_{j=1}^{m} u_{i j}\right) \\
& \sum_{i=1}^{n} \sum_{j=1}^{m} M_{i j}=\left(\sum_{i=1}^{n} \sum_{j=1}^{m} l_{i j}, \sum_{i=1}^{n} \sum_{j=1}^{m} m_{i j}, \sum_{i=1}^{n} \sum_{j=1}^{m} u_{i j}\right) \\
& {\left[\sum_{i=1}^{n} \sum_{j=1}^{m} M_{i j}\right]^{-1}=\left(\frac{1}{\sum_{i=1}^{n} \sum_{j=1}^{m} u_{i j}}, \frac{1}{\sum_{i=1}^{n} \sum_{j=1}^{m} m_{i j}}, \frac{1}{\sum_{i=1}^{n} \sum_{j=1}^{m} l_{i j}}\right)}
\end{aligned}
$$

Step degree of possibility calculation: The values of fuzzy synthetics extents $S_{i}$ are compared and the degree of possibility of $S_{j}=\left(l_{j}, m_{j}, u_{j}\right) \geq S_{i}=\left(l_{i}, m_{i}, u_{i}\right)$, noted $V\left(S_{j} \geq S_{i}\right)$ is calculated. This calculation is done using the following formula:

$$
V\left(S_{j} \geq S_{i}\right)=\left\{\begin{array}{cc}
1, & \text { if } m_{j} \geq m_{i} \\
0, & \text { if } l_{i} \geq u_{j} \\
\frac{l_{i}-u_{j}}{\left(m_{i}-u_{j}\right)-\left(m_{i}-l_{i}\right)}, & \text { otherwise }
\end{array}\right.
$$

The degree of possibility for a fuzzy number $M$ to be greater than $k$ fuzzy numbers $\left\{M_{s}\right\}_{1 \leq s \leq k}$ is defined by:

$$
V\left(M \geq M_{1}, M_{2}, \ldots, M_{k}\right)=\left[V\left(M \geq M_{1}\right), V\left(M \geq M_{2}\right), \ldots, V\left(M \geq M_{k}\right)\right]=\min V\left(M \geq M_{s}\right)
$$

Step of determination of weight vector: To compare $S_{i}$ and $S_{j}, d^{\prime}\left(C_{i}\right)$ is defined as follows:

$$
d^{\prime}\left(C_{i}\right)=\min V\left(S_{i} \geq S_{k}\right) \text { wherek }=1,2, \ldots, \operatorname{nand} k \neq i
$$

The weight vector containing the weights of the criteria is given by:

$$
W^{\prime}=\left(d^{\prime}\left(C_{1}\right), d^{\prime}\left(C_{2}\right), \ldots, d^{\prime}\left(C_{n}\right)\right)^{T} \text { where } C_{1}, C_{2}, \ldots, C_{n} \text { are the criteria }
$$

After normalization, the normalized weight vector $W$ from the weight vector $W^{\prime}$ is defined as follows:

$$
W=\left(d\left(C_{1}\right), d\left(C_{2}\right), \ldots, d\left(C_{n}\right)\right)^{T}
$$




\section{RESULTS AND DISCUSSION}

This section describes and discussesthe different steps and results of the application of FAHP method to evaluate tenders for the realization of IT master plan.

\subsection{Criteria, Sub-Criteria and Preference Degrees}

The identification of criteria, sub-criteria and their weights is a crucial step toward the implementation of the FAHP method. In this study, the approach adopted has been to consult several tender documents gathering expertise from many experts about criteria, sub-criteria and weighting. Tender documents about IT master plan realization from different countries have been consulted. The process of identification has been done in two main phases. In the first phase, the expertise of many experts who have participated in the drafting of the several consulted tender documents allowed identifying criteria, sub-criteria and weights.

A similar work has been done in the second phase to consolidate the results of the first phase and establish the definitive list of criteria, sub-criteria and their weights. The Table 2 contains some of the many tender documents that have been consulted.

This approach allowed, on the one hand, to identify all criteria and sub criteria and on the other hand to have a good appreciation of preference degree of each pair of criteria and each pair of sub-criteria for a given criterion. The Figure 1 presents in a hierarchical structure all criteria and sub-criteria for the implementation of FAHP method.

Table 2. Some tender documents consulted

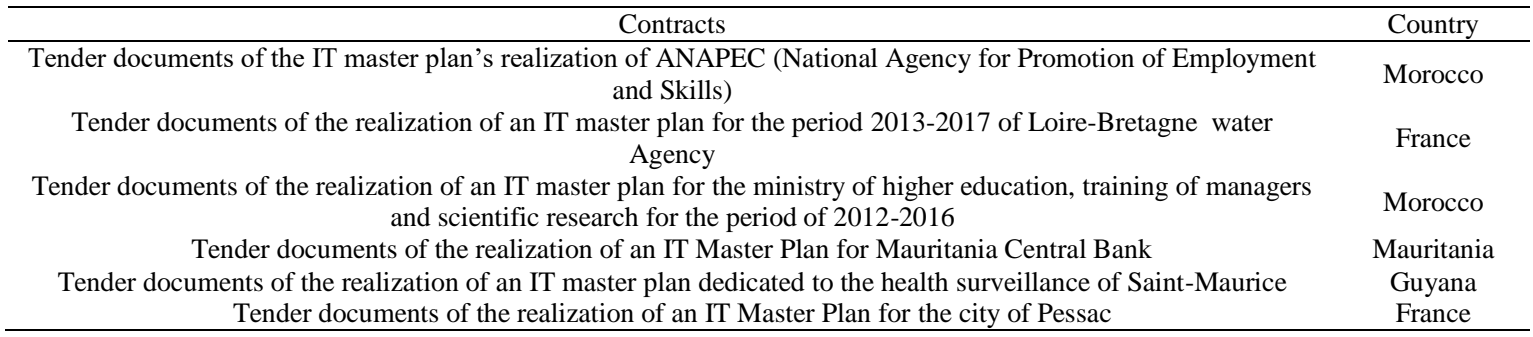

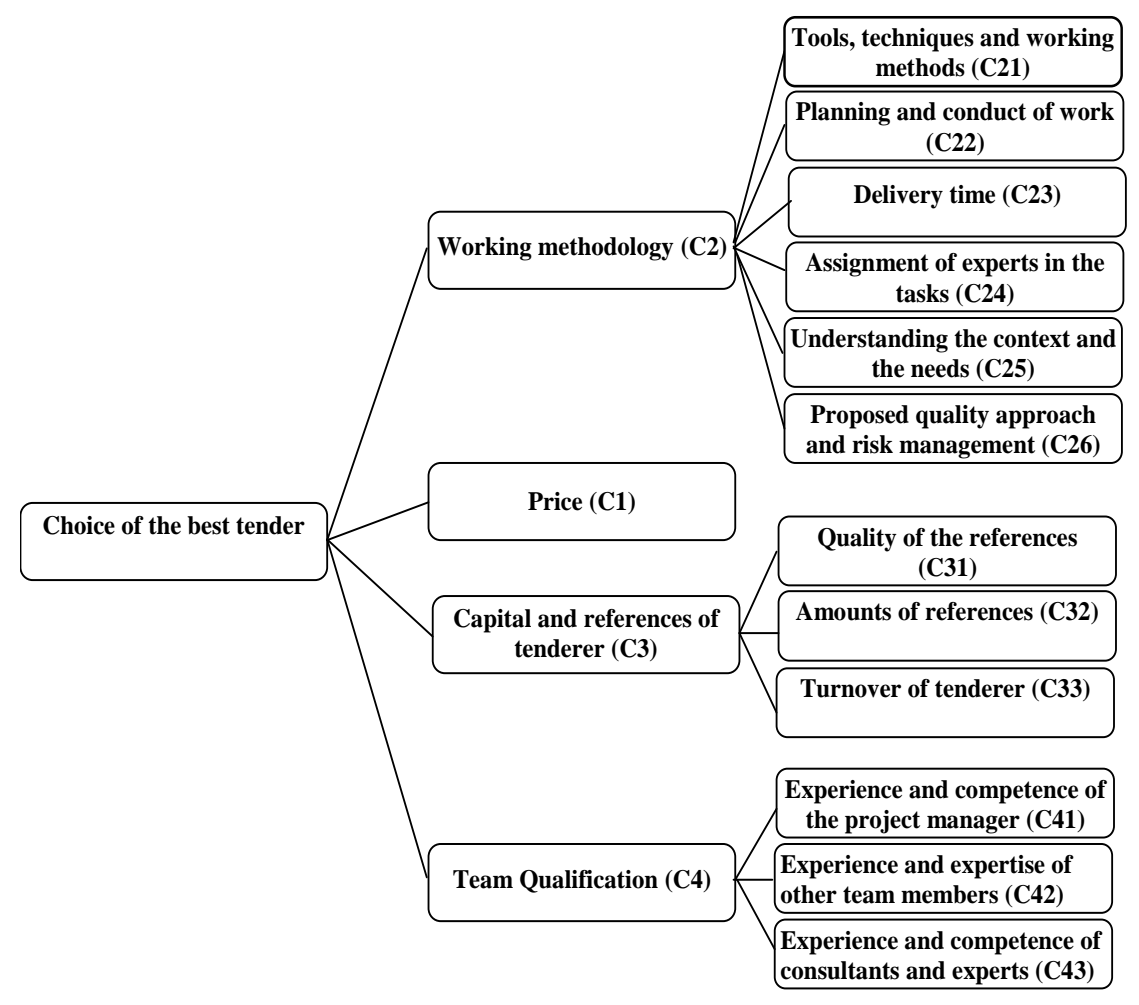

Figure 1. Hierarchy of Criteria and Sub-criteria for Evaluation Tenders 


\subsection{Construction of Judgment Matrix of Criteria and Determination of the Priority Vector}

In this sub-section, the judgment matrix of criteria and the calculation of his priority vector are presented.The Tables 3 and 4 contain respectively the judgment matrix of criteria and the calculations of the priority vector. The most important criterion is the criterion "Price" with a weight of 0.51 . It is followed by the criteria "Team Qualifications" and "Working methodology" having respectively weight of 0.194 and 0.178 .

Table 3. Judgment Matrix of Criteria

\begin{tabular}{ccccccccccccc}
\hline & & Price & \multicolumn{4}{c}{ Working methodology } & \multicolumn{2}{c}{ Capital and references } & \multicolumn{2}{c}{ Team Qualification } \\
Price & 1 & 1 & 1 & $3 / 2$ & 2 & $5 / 2$ & 2 & $5 / 2$ & 3 & $3 / 2$ & 2 & $5 / 2$ \\
\hline Working methodology & $2 / 5$ & $1 / 2$ & $2 / 3$ & 1 & 1 & 1 & $1 / 2$ & $1 / 1$ & $3 / 2$ & $2 / 3$ & 1 & 2 \\
Capital and references & $1 / 3$ & $2 / 5$ & $1 / 2$ & $2 / 3$ & 1 & 2 & 1 & 1 & 1 & $1 / 2$ & $2 / 3$ & 1 \\
Team Qualification & $2 / 5$ & $1 / 2$ & $2 / 3$ & $1 / 2$ & $1 / 1$ & $3 / 2$ & 1 & $3 / 2$ & 2 & 1 & 1 & 1 \\
\hline
\end{tabular}

Table 4. Calculation of Priority Vector of Criteria

\begin{tabular}{ccccccc}
\hline Criteria & FSE & Lower(Si) & Middle(Si) & Upper $(\mathrm{Si})$ & Weight $\left(\mathrm{d}^{\prime}(\mathrm{Si})\right)$ & WeightNormalized \\
\hline $\mathrm{C} 1$ & $\mathrm{~S} 1$ & 0.251 & 0.415 & 0.644 & 1 & 0.513 \\
$\mathrm{C} 2$ & $\mathrm{~S} 2$ & 0.108 & 0.193 & 0.369 & 0.348 & 0.178 \\
$\mathrm{C} 3$ & $\mathrm{~S} 3$ & 0.105 & 0.169 & 0.322 & 0.223 & 0.114 \\
$\mathrm{C} 4$ & $\mathrm{~S} 4$ & 0.121 & 0.221 & 0.369 & 0.379 & 0.194 \\
\hline
\end{tabular}

\subsection{Construction of Judgment Matrices of Sub-Criteria and Determination of Priority Vectors}

This sub-section addresses the calculations of sub-criteria's weights. The case of the sub-criteria of criterion "Working Methodology" is presented in Tables 5 and 6 and the Table 7 contains the weights of all sub-criteria. The Tables 5 and 6 present respectively the judgment matrix of sub-criteria of criterion "Work Methodology (C2)" and the calculations of the associated priority vector.

Table 5. Judgment Matrix of Sub-criteria of Criterion "Working Methodology"

\begin{tabular}{ccccccccccccccccccc}
\hline & & $\mathrm{C} 21$ & \multicolumn{1}{c}{} & $\mathrm{C} 22$ & \multicolumn{1}{c}{$\mathrm{C} 23$} & \multicolumn{4}{c}{$\mathrm{C} 24$} & \multicolumn{3}{c}{$\mathrm{C} 25$} & \multicolumn{3}{c}{$\mathrm{C} 26$} \\
\hline $\mathrm{C} 21$ & 1 & 1 & 1 & $3 / 2$ & 2 & $5 / 2$ & 2 & $5 / 2$ & 3 & $3 / 2$ & 2 & $5 / 2$ & $1 / 2$ & 1 & $3 / 2$ & 2 & $5 / 2$ & 3 \\
$\mathrm{C} 22$ & $2 / 5$ & $1 / 2$ & $2 / 3$ & 1 & 1 & 1 & $1 / 2$ & 1 & $3 / 2$ & 1 & $3 / 2$ & 2 & $1 / 2$ & $2 / 3$ & 1 & $1 / 2$ & 1 & $3 / 2$ \\
$\mathrm{C} 23$ & $1 / 3$ & $2 / 5$ & $1 / 2$ & $2 / 3$ & 1 & 2 & 1 & 1 & 1 & $2 / 5$ & $1 / 2$ & $2 / 3$ & $2 / 5$ & $1 / 2$ & $2 / 3$ & $2 / 3$ & 1 & 2 \\
$\mathrm{C} 24$ & $2 / 5$ & $1 / 2$ & $2 / 3$ & $1 / 2$ & $2 / 3$ & 1 & $3 / 2$ & 2 & $5 / 2$ & 1 & 1 & 1 & $2 / 5$ & $1 / 2$ & $2 / 3$ & $1 / 2$ & 1 & $3 / 2$ \\
$\mathrm{C} 25$ & $2 / 3$ & 1 & 2 & 1 & $3 / 2$ & 2 & $3 / 2$ & 2 & $5 / 2$ & $3 / 2$ & 2 & $5 / 2$ & 1 & 1 & 1 & $3 / 2$ & 2 & $5 / 2$ \\
$\mathrm{C} 26$ & $1 / 3$ & $2 / 5$ & $1 / 2$ & $2 / 3$ & 1 & 2 & $1 / 2$ & 1 & $3 / 2$ & $2 / 3$ & 1 & 2 & $2 / 5$ & $1 / 2$ & $2 / 3$ & 1 & 1 & 1 \\
\hline
\end{tabular}

Table 6. Calculation of Priority Vector of Sub-criteria of Criterion "Working Methodology"

\begin{tabular}{ccccccc}
\hline Criteria & FSE & Lower $(\mathrm{Si})$ & Middle(Si) & Upper $(\mathrm{Si})$ & Weight $(\mathrm{d}$ '(Si)) & Weight Normalized \\
\hline $\mathrm{C} 21$ & $\mathrm{~S} 1$ & 0.241 & 0.411 & 0.669 & 1 & 0.300 \\
$\mathrm{C} 22$ & $\mathrm{~S} 2$ & 0.110 & 0.212 & 0.380 & 0.412 & 0.124 \\
$\mathrm{C} 23$ & $\mathrm{~S} 3$ & 0.098 & 0.165 & 0.339 & 0.285 & 0.086 \\
$\mathrm{C} 24$ & $\mathrm{~S} 4$ & 0.122 & 0.212 & 0.364 & 0.382 & 0.117 \\
$\mathrm{C} 25$ & $\mathrm{~S} 5$ & 0.203 & 0.355 & 0.620 & 0.871 & 0.262 \\
$\mathrm{C} 26$ & $\mathrm{~S} 6$ & 0.101 & 0.183 & 0.380 & 0.380 & 0.114 \\
\hline
\end{tabular}


Table 7. Summary Table of the Weights of Sub-criteria

\begin{tabular}{|c|c|c|c|c|c|c|}
\hline \multicolumn{7}{|c|}{ Criterion Working methodology (C2) } \\
\hline Sub-criterion & $\mathrm{C} 21$ & $\mathrm{C} 22$ & $\mathrm{C} 23$ & $\mathrm{C} 24$ & $\mathrm{C} 25$ & $\mathrm{C} 26$ \\
\hline Weight of sub-criterion & 0.300 & 0.124 & 0.086 & 0.115 & 0.262 & 0.114 \\
\hline \multicolumn{7}{|c|}{ Criterion Capital and References (C3) } \\
\hline Sub-criterion & C31 & C32 & C33 & & & \\
\hline Weight of sub-criterion & 0.558 & 0.097 & 0.345 & & & \\
\hline \multicolumn{7}{|c|}{ Criterion Team Qualification (C4) } \\
\hline Sub-criterion & $\mathrm{C} 41$ & $\mathrm{C} 42$ & $\mathrm{C} 43$ & & & \\
\hline Weight of sub-criterion & 0.345 & 0.558 & 0.097 & & & \\
\hline
\end{tabular}

The Table 7 displays the weights of the sub-criteria of each criterion. The criterion "Price" has no sub-criterion therefore it doesn't appear in the table.

\subsection{Comparison of Tenders and Determination of the Best}

This section consists in making a test with three tenders $O_{1}, O_{2}, O_{3}$. The Table 8 gives the comparison matrix of the three tenders according the criterion "Price" and the weights of tenders.

Table 8. Comparison Matrix of Tenders According Criterion "Price" and the Weight Vector

\begin{tabular}{ccccccccccc}
\hline$C 1$ & & $O_{1}$ & & & $O_{2}$ & & & $O_{3}$ & $W_{C 1}$ \\
\hline$O_{1}$ & 1 & 1 & $1 / 2$ & 1 & $3 / 2$ & $3 / 2$ & 2 & $5 / 2$ & 1 & 1 \\
$O_{2}$ & 1 & 2 & 1 & 1 & 1 & $1 / 2$ & 1 & $3 / 2$ & 1 & 0,78927766 \\
$O_{3}$ & $1 / 2$ & $2 / 3$ & $2 / 3$ & 1 & 2 & 1 & 1 & 1 & $1 / 2$ & 0,63865097 \\
\hline
\end{tabular}

For the criteria which have sub-criteria, the Table 9 contains the weights of the tenders according to sub-criteria of each criterion. The weight of tenders according criteria that have sub-criteria are calculated by the weighted sum of the weights of sub-criteria and the weights of tenders according sub-criteria [41].

Table 9. Results of the Comparison of Tenders at Sub-criteria Level

\begin{tabular}{|c|c|c|c|c|c|c|c|}
\hline \multicolumn{8}{|c|}{ Criterion Working methodology (C2) } \\
\hline Sub-criterion & $\mathrm{C} 21$ & $\mathrm{C} 22$ & $\mathrm{C} 23$ & $\mathrm{C} 24$ & $\mathrm{C} 25$ & $\mathrm{C} 26$ & \\
\hline Weight of sub-criterion & 0.300 & 0.124 & 0.086 & 0.115 & 0.261 & 0.114 & \\
\hline Tender & \multicolumn{6}{|c|}{ Tenders weights at sub-criteria level } & Weight of tender \\
\hline$O_{1}$ & 1 & 1 & 0.098 & 0.905 & 0.109 & 1 & 0.679 \\
\hline $\mathrm{O}_{2}$ & 0.472 & 0.109 & 1 & 1 & 1 & 0.482 & 0.672 \\
\hline$O_{3}$ & 0 & 0.201 & 1 & 0.328 & 0.201 & 0.684 & 0.278 \\
\hline \multicolumn{8}{|c|}{ Criterion Capital and References (C3) } \\
\hline Sub-criterion & $\mathrm{C} 31$ & $\mathrm{C} 32$ & $\mathrm{C} 33$ & & & & \\
\hline Weight of sub-criterion & 0.558 & 0.097 & 0.345 & & & & \\
\hline Tender & \multicolumn{6}{|c|}{ Tenders weights at sub-criteria level } & Weights of tenders \\
\hline$O_{1}$ & 1 & 1 & 0 & & & & 0.655 \\
\hline $\mathrm{O}_{2}$ & 0.359 & 0.844 & 0.472 & & & & 0.445 \\
\hline$O_{3}$ & 0.334 & 0.171 & 1 & & & & 0.548 \\
\hline \multicolumn{8}{|c|}{ Criterion Team Qualification (C4) } \\
\hline Sub-criterion & $\mathrm{C} 41$ & $\mathrm{C} 42$ & $\mathrm{C} 43$ & & & & \\
\hline Weight of sub-criterion & 0.345 & 0.558 & 0.097 & & & & \\
\hline Tender & \multicolumn{6}{|c|}{ Tenders weights at sub-criteria level } & Weights of tenders \\
\hline$O_{1}$ & 0 & 1 & 1 & & & & 0.655 \\
\hline $\mathrm{O}_{2}$ & 1 & 0.904 & 0.495 & & & & 0.898 \\
\hline$O_{3}$ & 0.756 & 0.795 & 0.502 & & & & 0.753 \\
\hline
\end{tabular}


Table 10. Results of the comparison of tenders at criteria level

\begin{tabular}{ccccc}
\hline & $O_{1}$ & $O_{2}$ & $O_{3}$ & Weight of criterion \\
\hline $\mathrm{C} 1$ & 1 & 0.78927766 & 0.63865097 & 0.512830235 \\
$\mathrm{C} 2$ & 0.67868134 & 0.67199679 & 0.27849382 & 0.178473208 \\
$\mathrm{C} 3$ & 0.65535434 & 0.44492022 & 0.54795857 & 0.114387558 \\
$\mathrm{C} 4$ & 0.65535434 & 0.89772603 & 0.75305711 & 0.194308999 \\
Scores of tender & 0.8362623 & 0.75002845 & 0.58622863 & \\
\hline
\end{tabular}

The final results according to criteria are displayed in the Table 10. The tender $O_{1}$ is the best with a score of 0.836 .As we did'nt find any paper which deals with the selection of the best tender during awarding contracts of IT Master plan's realisation, we have conducted a comparison between the resultswith those obtained using AHP method. The weights of criteria and sub-criteria and the scores of tenders are closer when using FAHP method.

\section{CONCLUSION}

The computer system has become one of the centerpieces in the functioning of organizations hence the importance of an IT master plan to manage its development. Aware the importance of the IT master plan, many organizations are working on the establishing of an IT master plan and they increasingly use tendering to find a provider able to put in place an effective IT Master plan. This allows them to create a competition between several providers with a view to choosing the one that proposes the best proposal.

However, as others public and private contracts, contracts awarding of IT master plan's realization faces the problematic of choosing the best tender among those proposed by the bidders.

The present work is a response to this problematic by proposing a decision support tool that has been thoughtfully designed for facilitating the choice of the best tender. Such work aims to improve the step of the evaluation of tenders of IT master plan's realization and endow the organizations with effective IT Master Plan in order to increase the performance of their information system.

In the era of the use of information and communication technologies (ICT) where almost all private and public organizations have an information system, the number of contracts concerning the realization of IT master plan is increasing considerably reflecting the importance of this proposed decision support tool.

\section{REFERENCES}

[1] Oztaysi B. A decision model for information technology selection using AHP integrated TOPSIS-Grey: The case of content management systems. Knowl.-Based Syst. March 2014.

[2] Koning P, De Meerendonk A. The impact of scoring weights on price and quality outcomes: An application to the procurement of Welfare-to-Work contracts. Eur. Econ. Rev.October 2014; 71: 1-14.

[3] Auriol E.Corruption in procurement and public purchase. Int. J. Ind. Organ. September 2006; 24(5): 867-885.

[4] Ameyaw C, Mensah S.Curbing Corruption in the Public Procurement Process in Ghana. Public Policy Adm. Res. 2013; 3(5): 44-53.

[5] Ciribini ALC, et al. An Innovative Approach to e-public Tendering Based on Model Checking.Procedia Econ. Finance. 2015; 21: 32-39.

[6] Woods GG. Financial Management and cost accounting. Cape Town: University of Stellenbosch. 2008.

[7] Watt D, et al. Identifying key factors in the evaluation of tender for projects and servic. International Journal of Project Management. April 2009; 27: 250-260.

[8] Costa C, et al. Facililating bid evaluation in public call for tenders: A socio-clinical approach. Omega. June 2002; 30: $227-242$.

[9] Watt D, et al. The relative importance of tender evaluation and contractor selection criteria. International Journal of Project Management. January 2010; 28: 51-60.

[10] Mafakheri F, Breton M., Ghoniem, A. Supplier selection-order allocation: A two-stage multiple criteria dynamic programming approach. International Journal of Production Economics. 2011; 52-57.

[11] Ordoobadi, SM. Application of AHP and Taguchi loss functions in supply chain. Industrial Management and Data Systems. 2010; 251-126.

[12] Saaty RW. The analytic hierarchy process—-what it is and how it is used. Math. Model. 1987; 9(3): 161-176.

[13] Dalalah D, et al. Application of the Analytic Hierarchy Process (AHP) in multi-criteria analysis of the selection of cranes. Jordan J. Mech. Ind. Eng. 2010; 4(5): 67-578

[14] Ahmad N, Laplante PA. Software project management tools: making a practical decision using AHP. Software Engineering Workshop, SEW'06. 30th Annual IEEE/NASA. 2006; 76-84.

[15] Baohui J, Yuxin Z, Xiang L. Research on Zonal Inspection Intervals of Civil Aircraft Based on Improved FAHP. Indonesian Journal of Electrical Engineering and Computer Science. 2014; 12(1): 129-134. 
[16] Salem MS. An Application of the Analytic Hierarchy Process to Determine Benchmarking Criteria for Manufacturing Organisations. Int. J. Trade Econ. Finance, 2010; 1(1)

[17] Osiro L, et al. A fuzzy logic approach to supplier evaluation for development. Int. J. Prod. Econ. July 2014; 153: 95-112.

[18] Hung Q and Fung J. Prioritizing the Factor Weights Affecting Tourism Performance by FAHP. Int. J. Eng. Bus. Manag. 2013.

[19] Demirel T, et al. Fuzzy analytic hierarchy process and its application.in Fuzzy Multi-Criteria Decision Making, Springer, 2008; 53-83.

[20] Krasniqi S. Public procurement procedures and its cycles. Int. J. Res. Rev. Appl. Sci. 2012; 10(1).

[21] Wong JKW, Li H. Application of the analytic hierarchy process (AHP) in multi-criteria analysis of the selection of intelligent building systems. Build. Environ..January 2008; 43(1): 108-125.

[22] Tsai K, Chou F.Developing a Fuzzy Multi-attribute Matching and Negotiation Mechanism for Sealed-bid Online Reverse Auctions. J. Theor. Appl. Electron. Commer. Res. 2011; 6(3): 3-14.

[23] Diabagaté A, Azmani A, El Harzli M.Tendering Process: Improvement of Analysis and Evaluation of Tenders based on the Use of Fuzzy Logic and Rule of Proportion. International Journal of Computer Applications, September 2014; 101(14): 43-50.

[24] Priya P, et al. E-Procurement System with Embedded Supplier Selection DSS for an Automobile Manufacturing Industry. Int. J. Database Manag. Syst. April 2012; 4(2): 85-96.

[25] Atanasova-Pacemska T, Lapevski M, Timovski R. Analytical Hierarchical Process (AHP) method application in the process of selection and evaluation. International Scientific Conference Gabrovo. November 2014.

[26] Aydin S, Kahraman C. Multiattribute supplier selection using fuzzy analytic hierarchy process. Int. J. Comput. Intell. Syst. 2010; 3(5): 553-565.

[27] Chan FTS, Kumar N. Global supplier development considering risk factors using fuzzy extended AHP-based approach. Omega International Journal of Management Science. 2007; 35: 417-431.

[28] Ayhan MB.A Fuzzy Ahp Approach for Supplier Selection Problem: A Case Study In A Gearmotor Company. Int. J. Manag. Value Supply Chains. September 2013; 4(3): 11-23.

[29] Tas A. A Fuzzy AHP approach for selecting a global supplier in pharmaceutical industry. Afr. J. Bus. Manag. April $2012 ; 6(14)$

[30] Shaw K, et al. Supplier selection using fuzzy AHP and fuzzy multi-objective linear programming for developing low carbon supply chain. Expert Systems with Applications. July 2012; 39(9): 8182-8192.

[31] Liu L, Chen H.Comprehensive Evaluation of Examination Quality Based on Fuzzy AHP. Indonesian Journal of Electrical Engineering and Computer Science.2013; 11(9): 5384-539.

[32] Taylan O, et al. Construction projects selection and risk assessment by fuzzy AHP and fuzzy TOPSIS methodologies. Appl. Soft Comput. April 2014; 17: 105-116.

[33] LeeAHI, et al. A fuzzy AHP and BSC approach for evaluating performance of IT department in the manufacturing industry in Taiwan. Expert Systems with Applications. 2008; 34(707): 96-107.

[34] ZadehLA. Fuzzy Sets. Information Control, 1965; 8: 338-353.

[35] Naghadehi MZ, et al. The application of fuzzy analytic hierarchy process (FAHP) approach to selection of optimum underground mining method for Jajarm Bauxite Mine, Iran. Expert Systems with Applications. 2009; 36: 8218 8226.

[36] ErtugrulI, KarakasogluN. The fuzzy analytic hierarchy process for supplier selection and an application in a textile company. In Proceedings of $5^{\text {th }}$ international symposium on intelligent manufacturing systems, 2006; 195-207.

[37] Chang DY. Applications of the extent analysis method on fuzzy AHP. Eur. J. Oper. Res. 1996; 95(3): 649-655.

[38] Jia J, et al. The low carbon development (LCD) levels' evaluation of the world's 47 countries (areas) by combining the FAHP with the TOPSIS method. Expert Systems with Applications. 2008; 39: 6628-6640.

[39] Saaty TL. Some mathematical concepts of the analytic hierarchy process. Behaviormetrika. 1991; 29: 1-9.

[40] Jalao ER, et al. A stochastic AHP decision making methodology for imprecise preferences. Information Science. June 2014; 270: 192-203.

[41] Lai W, et al. Study and implementation of fire sites planning based on GIS and AHP. Procedia Eng. January 2011; 11: pp. 486-495.

\section{BIOGRAPHIES OF AUTHORS}

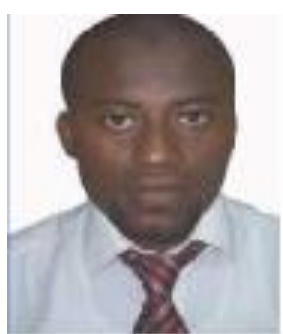

Dr. Amadou Diabagate received his Ph.D. in compter science (Artificial Intelligence and Big Data Science) in 2016 at the Faculty of Sciences and Technologies of Tangier (Morocco). Heis also state engineerin statistic and business intelligence. His research focuses on artificial intelligence, Big Data, data science and e-government (e-procurement). He has four scientific papers in international indexed journals and he has participated to international scientific congresses and conferences. 


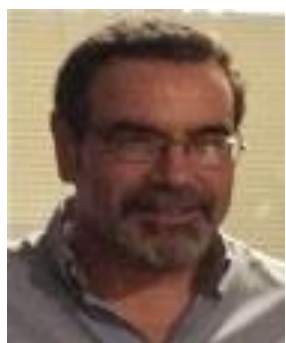

Dr. Abdellah Azmani received his Ph.D. in Industrial Computing at the University of Science and Technology of Lille (France) in 1991. He worked as a professor at the Ecole Centrale de Lille and at the Institute of Computer and Industrial Engineering from Lens. He is a member of the Laboratory of Automatics and Informatics of Lille (LAIL). He joined the Faculty of Sciences and Techniques of Tangier in 2004 where he practices as a professor of computer modeling and Artificial Intelligence. He has contributed to many scientific research projects and he elaborates and produces many IT solution for learning games, e-learning, Public Administration, good governance and decision support.

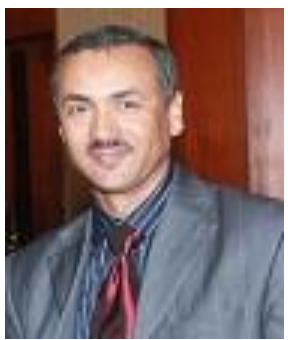

Dr. Mohamed El Harzli is associate professor at Faculty of Sciences and Technology of Tangier, Morocco. Hereceived his state doctorate in Instrumentation at Faculty of Science of Meknes (Morocco), after his PhD from the University of Lille (France) in Electronics. He has taught in several universities and graduate schools in France and Morocco.

He received recently his Master in "Intellectual Property Rights" set up by the World Intellectual Property Organization (WIPO) and the African Intellectual Property Organization (OAPI). 